\title{
Research on Constructing Innovation-Driven Development Evaluation System Based on the Essential Component of Intellectual Property
}

\author{
Yueping Du, Yilin Wang \\ School of Economics \& Management, Xidian University, Xi'an, China \\ Email: xidianyilin@163.com
}

How to cite this paper: $\mathrm{Du}$, Y.P. and Wang, Y.L. (2017) Research on Constructing Innovation-Driven Development Evaluation System Based on the Essential Component of Intellectual Property. Open Journal of Business and Management, 5, 149-158.

http://dx.doi.org/10.4236/ojbm.2017.51014

Received: December 10, 2016

Accepted: January 10, 2017

Published: January 13, 2017

Copyright $\odot 2017$ by authors and Scientific Research Publishing Inc. This work is licensed under the Creative Commons Attribution International License (CC BY 4.0).

http://creativecommons.org/licenses/by/4.0/

\begin{abstract}
The innovation-driven development strategy based on the essential component of intellectual property is an important strategy in the new period of China. Based on the understanding of generalized innovation and the model of input-output, the article analyzes the support for innovation-driven development of intellectual property, and from three aspects of intellectual property: investment, conversion and output, starting to build a model of three first-level indicators and twenty-four secondary indicators to evaluate the innovation-driven economic development based on the essential component of intellectual property.
\end{abstract}

\section{Keywords}

Intellectual Property, Innovation-Driven, Economic Development, Evaluation System

\section{Introduction}

Since the reform and opening-up, economy of China developed rapidly, and the growth of GDP remained high; however, the shortage of resources and environmental pollution is unavoidable. The enormous pressure of environment requires us to rethink the mode of economic development. We should change the way of promoting economic growth gradually from "factor-driven", "investment-driven" to "innovation-driven". The 18th National Congress of the Communist Party of China clearly indicated that we should play the important role fully of technological innovation in economic growth to change the mode of economic development, and emphasized the implementation of innovation-driven development strategy. The Third Plenary Session of the 18th CPC Central Committee clearly indicated once again that it is necessary to strengthen the application and protection of intellectual property rights in order to deepen the reform of the science and technology system. Intellectual property is the product of modern 
commodity economy and the development of science and technology. As one of the law-protected innovations, intellectual property is playing an important role in economic growth. "The state council's several opinions on accelerating the construction of the power of intellectual property rights under the new situation" in 2016, pointed out that to improve the development of evaluation system, intellectual property products will be gradually incorporated into the national economic accounting, and intellectual property indicators will be incorporated into the national economic and social development planning, constructing an innovation-driven development evaluation system based on the essential component of intellectual property. "Opinion" indicated that, intellectual property rights is playing a more and more important role in the growth of the national economy.

Therefore, it is very important to understand and evaluate the regional innovationdriven development based on the essential component of intellectual property, and to establish a comprehensive evaluation index system which emphasizes the outstanding of intellectual property rights. First of all, getting a clear understanding of the concept of innovation-driven development is very important, then we explored the supporting mechanism of intellectual property on innovation-driven development and finally built a prominent role of intellectual property in the comprehensive evaluation index system. Therefore, this article mainly researches the intellectual property evaluation indexes to construct evaluation system of innovation-driven development. This is a new exploration of the theory and practice of innovation-driven development, which also possesses practical significance to promote regional economic development.

\section{Literature Review on Evaluation of Innovation-Driven Development}

In abroad, the EU Innovation Policy Research Center developed a European Innovation Scoreboard, which is currently considered as the most representative of the mature Innovation Evaluation System. The Main Index System of EIS is reflected in five aspects, the innovation-driven, knowledge creation, innovation, technology and intellectual property. Since then, the EU has launched the "Global Innovation Scoreboard" and "Innovative Union Scoreboard", to improve Innovation evaluation system further.

Compared with foreign mature evaluation system, the domestic research on the innovation-driven development own their characteristics of each, according to the difference of evaluation point of view and logical thinking. Wu, Y. (2014) Constructed the evaluation system of urban innovation-driven development, including 4 first-level indicators (basic conditions for innovation, innovation input, innovation output and innovation impacts), 13 secondary indicators and 46 third-level indicators [1]. Wei, Y.P. (2014) established the innovation-driven evaluation index system of innovative city, including 4 first-level indicators (main elements of innovation-driven, resource elements of innovation-driven, effect elements of innovation-driven and environment elements of innovation-driven), 14 secondary indicators and 19 third-Level indicators [2]. On the basis of the innovation-driven theory, Wang, W. (2015) built a regional innovation-driven evaluation system consists of four aspects, which is innovation-driven, innovation-driven process, innovation-driven environment and innovation-driven per- 
formance, also evaluated and compared the innovation-driven capability of China's 31 provinces by principal component analysis method [3]. Yin, M. J. (2015) based on the connotation of innovation-driven development and the ideas of input-output, built the evaluation model of provincial innovation-driven development, which used the GDP index to measure the volume and level of economic development, and used the sales revenue of new product, number of admissibility for three types of patent applications and transaction amount of technology market to measure the level of the regional technology innovation [4]. In accordance with the "Impact-Effect-output-input" idea, $\mathrm{Hu}$, C. P. (2016) established the innovative evaluation system of Shaanxi Province, including 4 first-level indicators (impact indicators, effect indicators, output indicators, input indicators), 11 secondary indicators and 38 third-level indicators [5]. Li, Q. (2016) compared the status of input and output based on provincial innovation-driven development, and built an evaluation system of the innovation-driven development of the provincial area. This evaluation system comprises 6 first-level indicators (social development, R \& D resources, market efficiency, economic industry, research, technical support), 17 secondary indicators and 37 third-level indicators. She made a comparative study of innovation-driven development in Jiangsu, Beijing, Shanghai, Zhejiang and Guangdong Provinces [6].

This shows that there isn't a unified index system for the evaluation of innovation-driven development in China. Most researchers start from the macroscopic point of view and comprehensively evaluate the process of innovation-driven development. The evaluation index covers a wide range, but due to that many indicators cannot be quantified, the process is too dependent on qualitative and subjective methods.

Based on the idea of input-output, this paper builds up the evaluation index system around the process, creatively constructs innovation-driven development evaluation system based on the essential component of intellectual property in our country. In this research, we will focus on the intellectual property right, and emphasize the role of intellectual property right in the innovation-driven development.

\section{The Support Mechanism Analysis of IP on Innovation-Driven Development}

Tian, L.P. (2013) pointed out that the implementation of innovation-driven development strategy and accelerate the economic development pattern is the same strain [7].

To realize the transformation from element-driven to innovation-driven, we must promote intellectual property as the growth factor, stimulate innovation vitality and promote the application of innovation results, so as to truly promote the promotion of economic development. Based on the theory of new economic growth, which reveals that the main source of economic growth is knowledge innovation and technological progress, and the direct goal of intellectual property rights is to stimulate intellectual property innovation and technological progress.

To understand the supporting role of intellectual property in innovation-driven development, we should have a clear understanding of innovation-driven development. The word "innovation" is first published in the book named "the Theory of Economic Development" in 1912, which is written by the American economist Schumpeter, he 
believes that innovation is the essence of economic development and emphasizes the important role of innovation in the development process. Zhang, L.W. (2013) considered that the innovation solved two basic problems of the economic development: First, the problem of diminishing returns factor of production, the second is about the bottleneck problem of scarce resources [8]. This is because that the innovation is a change which brings a new combination of production factors into the production system, it will inevitably break the original track of economic development, thereby solving the above two problems. Therefore, we can clearly know that innovation is the driving force of economic development. So what is the source of innovation? Intellectual Property Office Shen, Y.C. (2014) said that "innovation-driven development has two important issues, first of all is the question about the source for innovation, the second is the question about the final one kilometer innovation achievements into practical productivity conversion. Both of them are closely related to intellectual property rights In a sense, intellectual property rights is the source of innovation, the support of innovation-driven development, and also the connection between the innovation and the market. Besides, it is a very important link to achieve the goal from strong technology to strong industry and then to the strong economy" [9]. We believe that the broad innovation contains many aspects, such as knowledge and technology innovation, management innovation, system innovation and so on. The intellectual property is the most important content in knowledge and technology innovation. It refers to the exclusive right enjoyed by the right holder in the intellectual work. As a result, intellectual property rights owns an incentive mechanism, which protects owners' rights and interests, stimulates the continuous innovation activities, and drives economic growth further .

In order to construct an innovation-driven development evaluation system based on the essential component of intellectual property, we emphasize and study the impact of the development of intellectual property on the economic growth in generalized innovation. Therefore, the evaluation system constructed in this paper mainly embodies the relationship between intellectual property and economic growth. This article divides the intellectual property rights creation process into three stages, the first one is the investment stage of intellectual property creation, including capital investment, human capital investment, etc; the second one is the intellectual property creation stage, which means the mental labor innovation process; the third one is the output stage of intellectual property, which includes patents, trademarks and copyrights. The intellectual property outcomes produced through this process are transformed by appropriate platform mechanisms, and only the successfully transformed intellectual property can generate productivity, realize its market value and generate economic output. Through the above analysis, author believes that the mechanism of intellectual property rights and economic growth can be divided into three links: the first is the input link, the second is the conversion process, the third is the output link. Input link should include the creation of intellectual property investment and also the output of intellectual property results. Transformation is the most crucial step in the whole economic process. It is an important way to realize the commercialization and industrialization of intellectual property rights. In other words, the transformation directly determines 
whether the intellectual property rights can become the real productive forces. In the output link, because of the wide range of factors that the economic development involves, not only contains changes in factors of production inputs, but also contains the power, quality, environment and other factors of development, which is not conducive to quantitative statistics, so we only focus on the direct economic output, which gives us a more intuitive observation of the change of numbers in output as a result of the increase of input.

For the support mechanism analysis of IP on innovation-driven development, we can use Figure 1 to represent. Innovation-driven development emphasizes that development depends on innovation to drive. It's reflected in the contribution of innovation to economic development. The innovation-driven development evaluation system based on the essential component of intellectual property is mainly to measure the contribution of intellectual property to economic development. Therefore, the essence of the research we are investigating is the role of intellectual property in innovation-driven economic growth.

\section{The Constructing Principles of Innovation-Driven Development Evaluation System Based on the Essential Component of Intellectual Property}

\subsection{Scientific Principles}

The evaluation system should be able to effectively reflect the role of intellectual property rights in the innovation-driven development. The evaluation indicators should be set according to the mechanism of intellectual property rights and economic growth, fully reflect the input, transformation and output and highlight the focus with making a comprehensive coverage. In the process of determining the comprehensive evaluation index, a high level of field experts should be involved to ensure that each indicator has its overall representativeness. Only quantitative indicators that can be measured should be selected, to eliminate the strong subjectively qualitative indicators and ensure the

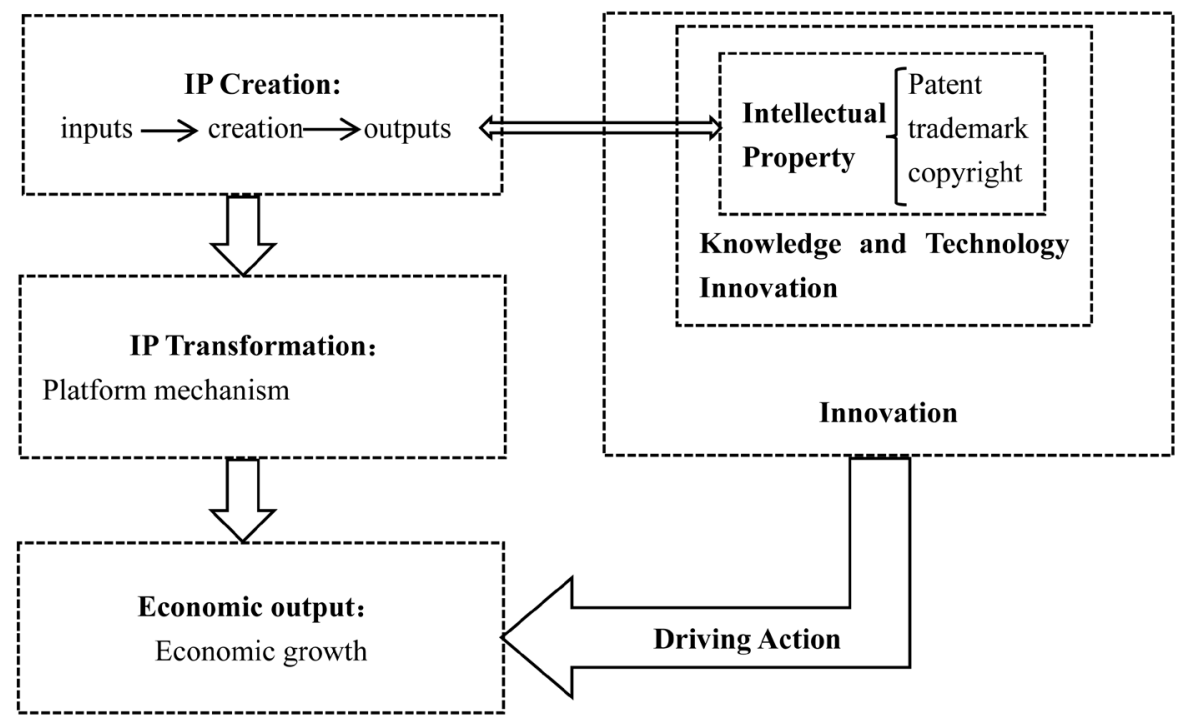

Figure 1. Support mechanism of IP on innovation-driven development. 
establishment of evaluation indexes being scientific, authoritative. At the same time, we should also use scientific evaluation methods, standardized evaluation procedures to ensure the objectivity of the evaluation during the evaluation process.

\subsection{Object-Oriented Principles}

The purpose of this research is to evaluate the level of regional economic growth driven by intellectual property rights of the innovation, to raise a new perspective which is different from the previous researches. With the advent of the knowledge economy, the work of IPR has become a necessary requirement to improve the core competitiveness of the region. The evaluation model to be constructed in this article can not only guide the government to carry out IPR evaluation, but also clarify the future development direction and the focus of work, the most important thing is to be able to improve the output of intellectual property rights further, and smooth the transformation of intellectual property operation channels, so as to promote regional economic growth and enhance the inherent driving force for regional development.

\subsection{Independence Principles}

In the evaluation system, the internal indicators should be distinct, and the evaluation indexes at the same level should be independent from each other, so as to avoid the overlapping of the indexes. Based on the input-output idea, according to the process of the interaction between intellectual property rights and economic growth, this research will be divided into three parts: input, transformation and output, and the three links are independent from each other. Three links within the target design, should also minimize the correlation between the indicators, to avoid cross-items.

\subsection{Operability Principles}

The meaning of each evaluation index should be clear. The indicators data can be obtained through the National Statistical Yearbook or the official release of the data, no direct data indicators should be easy to calculate through the available method to ensure the authority of the data. At the same time, each evaluation index should be able to carry out comparative analysis of horizontal and vertical, not only different indicators can be compared, but also the data of the same indicator from different time can be compared. It can not only make a comparative analysis of the contribution of intellectual property rights to economic growth in different regions, but also make a dynamic comparison of the evaluation results of different time in the same region. So as to comprehensively evaluate the role of intellectual property rights in economic growth from a historical and realistic perspective. In addition, a reasonable control of the size of the index system is necessary, to avoid the formation of a too large target group or a indicator system involving too complex level.

\section{Construction of Innovation-Driven Development Evaluation System Based on the Essential Component of Intellectual Property}

According to the preceding analysis of the support mechanism of intellectual property 
rights on innovation-driven development, we followed the principles of the index system construction and consulted a number of experts' advice, then established the innovation-driven development evaluation system based on the essential component of intellectual property which consists of 3 first-level indicators and 24 secondary indicators. The evaluation system mainly reflects the following three aspects: Firstly, investment and output of intellectual property innovation; Secondly, the transformation and operation of intellectual property rights; Thirdly, output of economic growth (Specific Index System Table 1).

Table 1. Innovation-driven development evaluation system based on the essential component of IP.

\begin{tabular}{|c|c|c|}
\hline $\begin{array}{l}\text { First-level } \\
\text { Indicators }\end{array}$ & Secondary Indicators & Indicator Description \\
\hline \multirow{11}{*}{$\begin{array}{l}\text { Input and } \\
\text { Output of the } \\
\text { Intellectual } \\
\text { Property } \\
\text { Innovation }\end{array}$} & $\mathrm{R} \& \mathrm{D}$ investment & Total government investment funds in technological research \\
\hline & $\mathrm{R} \& \mathrm{D}$ investment intensity & $\mathrm{R} \& \mathrm{D}$ expenditure as a percentage of GDP \\
\hline & Human resources investment & Total R \& D personnel \\
\hline & Human resource investment intensity & Number of R \& D personnel/total number of employees \\
\hline & Patent applications per ten thousand people & $\begin{array}{l}\text { The amount of patent applications in the year/population } \\
\text { (thousands of units) }\end{array}$ \\
\hline & Patents granted per ten thousand people & $\begin{array}{c}\text { The amount of patents granted in the year/population } \\
\text { (thousands of units) }\end{array}$ \\
\hline & PCT patent applications & The total PCT patent applications in the year \\
\hline & $\begin{array}{l}\text { Amount of invention patents accounted for the } \\
\text { proportion of patents granted }\end{array}$ & the amount of invention patents/patents granted in the year \\
\hline & Ownership of effective invention patents & $\begin{array}{l}\text { the effective amount of invention patents/population } \\
\text { (thousands of units) }\end{array}$ \\
\hline & Ownership of national well-known trademarks & the amount of trademarks approved by China famous trademark \\
\hline & Total copyright registration & Total number of applications for copyright registration \\
\hline \multirow{10}{*}{$\begin{array}{l}\text { Transformation } \\
\text { and Operation } \\
\text { of Intellectual } \\
\text { Property } \\
\text { Achievements }\end{array}$} & The amount of annual technical transaction contract & The total number of technology trading in the year \\
\hline & The amount of annual trademark transactions & The total number of trademark transferring and licensing in the year \\
\hline & The amount of annual copyright transaction contract & The total number of copyright trading contract registration in the year \\
\hline & Patent licensing revenue & The total amount of patent licensing income in the year \\
\hline & Trademark licensing revenue & The total amount of trademark licensing income in the year \\
\hline & Public service platform of IP & Number of IP public service platforms in the year \\
\hline & Intermediary service organization of IP & Number of IP intermediary agencies in the year \\
\hline & Professional personnel training institutions of IP & Number of institutions for the personnel training of IP in the year \\
\hline & The amount of state-level science and & The total number of national science and technology \\
\hline & technology business incubators & business incubators owned locally \\
\hline \multirow{4}{*}{$\begin{array}{c}\text { Economic } \\
\text { Growth } \\
\text { Output }\end{array}$} & GDP & The sum of the value added of industry in the year \\
\hline & Per capita GDP & $\begin{array}{l}\text { the total output in the year(the total GDP means the total output of } \\
\text { goods and social services)/total population in the year }\end{array}$ \\
\hline & GDP growth rate & $\begin{array}{l}\text { The added value of GDP } \\
\text { (compared with last year)/level of GDP last year }\end{array}$ \\
\hline & Billion investment in new GDP & The level of GDP improved by each billion investment \\
\hline
\end{tabular}




\subsection{Input and Output Indicators of the Intellectual Property Innovation}

Input and output indicators of IP innovation reflect the regional ability of IP creation, including 11 secondary indicators.

From the perspective of investment in R \& D funding, we set two indicators, " $R$ \& D investment", " $R \& D$ investment intensity" that reflect the financial resources investment conditions of IP creation in the area, and use the R \& D funding which accounted for the highest in the investment instead of all the funds invested. During the IP creation process, not only material inputs are needed, but also the human resource input. In this research, from the perspective of personnel investment, we set the "human resources investment", "human resources investment intensity" two indicators to reflect the input of intellectual property investment in human resources.

For the measurement of IPR outcomes, we start from researching the three main categories of IPR: patents, trademarks and copyrights. This article sets five indicators to reflect the regional outcome level of the patent, "Patent applications per ten thousand people", "Patents granted per ten thousand people" and "PCT patent applications" reflect the number of regional IP output, in which "PCT patent applications" refers to the applicant for a patent in China may file an international patent application or apply for a patent to a number of countries through PCT (Patent cooperation Treaty). Speaking of patents, according to the "Patent Law" which provides that China's patents are divided into three types, invention patents, utility model patents and design patents. The invention patents are generally regarded as the highest content of science and technology and the most valuable type of patent. Therefore, it is necessary to inspect the development of invention patent. Meanwhile, "patent law" states that term of the invention patent is 20 years from the date of filing. But in reality, not all the patents can be protected until the expiration of the term, part of the patent will early lose the legal effect because of the applicant voluntarily giving up. Thus, the number of valid invention patents is more being able to reflect the actual possession of the right of patent applicant than the number of invention patents. According to this, this article sets up the index of "Amount of invention patents accounted for the proportion of patents granted" and "Ownership of Effective Invention Patents" to examine the quality of intellectual property output.

In addition to the patents, intellectual property rights also include two main contents, trademarks and copyrights. We set two indicators "Ownership of National well-known trademarks" and "Total copyright registration". As the well-known trademark is the most valuable trademark and owns the highest quality, so we choose the amount of well-known trademarks to reflect the level of regional trademark development. The number of copyright registration reflects the active degree of cultural and artistic creation of citizens and legal persons, as well as the protection of intellectual property rights, and intuitively reflects the development of copyright in a region.

\subsection{Transformation and Operation Index of Intellectual Property}

The operational capabilities of Intellectual property reflect the ability of intellectual property into realistic productivity and the contribution rate of economic growth, which includes nine secondary indicators. 
From the aspects of intellectual property rights market trading volume, we set up three indicators, "The amount of annual technical transaction contract", "The amount of annual trademark transactions" and "The amount of annual copyright transaction contract", respectively reflect the transformation of intellectual property rights from the technology, trademarks and copyrights, showing the active degree of intellectual property transactions.

From the aspect of the quantity of intellectual property rights, based on the data availability, we set up two indicators, "Patent licensing revenue" and "Trademark licensing revenue", the patent licensing revenue reflects the technology transactions of the universities, research institutes and non-service inventors, while trademark licensing revenue reflects the development of the enterprise operating brand assets.

From the aspect of subject of intellectual property transformation, we set up four indicators, "Public Service Platform of IP", "Intermediary Service Organization of IP", "Professional personnel training institutions of IP" and "The amount of State-level Science and Technology Business Incubators". The intermediary services of intellectual property rights reflect the development of intellectual property intermediary service on the one hand and the maturity of the intellectual property economy on the other hand.

\subsection{Output Index of Economic Growth}

Output indicators of economic growth reflect a country or a region's ability to produce goods and services. A country or a region's economic growth is a result of the combined action of multiple factors. In the study of the reasons for promoting economic growth cannot exhaust all the elements, as the focus of this study is from a focal point to dig the contribution of intellectual property to economic growth effect.

There are many indicators about economic growth, the indicator system selecting different research angles will be different. Based on data availability, from a macro point of view, we select four indicators, "GDP”, "Per Capita GDP”, "GDP growth rate" and "Billion investment in new GDP", to fully reflect the level of regional economic growth.

\section{Conclusions}

Based on the implementation of intellectual property rights as an important part of innovation-driven development strategy, according to the input-output idea, this article builds a regional evaluation system of innovation-driven development from three aspects (intellectual property rights, transformation and economic growth), which include 3 first-level indicators and 24 secondary indicators. The index is objective, concrete and practical, which reflects and highlights the role of intellectual property rights in economic development, and consummates the research on the theory of innovation-driven development evaluation system.

Though the model doesn't contain the comprehensive index in the process of intellectual property development, the model is designed to focus on the intellectual property right, to study the process of driving economic development. The model with feasibility and practicality can explain and solve the problem to a large extent. According to the index system, we can use the appropriate method to evaluate the level of innova- 
tion-driven development of the provinces or cities.

In the future, we will select the typical provinces or cities to carry out empirical analysis, to reveal the important role of intellectual property rights in promoting the mode change of the economic development and advancing economic growth with scientific data. Constantly improving the model in practice, we will promote the implementation of the innovation-driven development strategy and make recommendations for the government.

\section{References}

[1] Wu, Y. and Li, W.J. (2014) Innovation-Driven Development Evaluation System. Opening Herald, 4, 88-92.

[2] Wei, Y.P. and Jia, Z.H. (2014) Evaluation Studies of innovation-Driven Elements Of Innovative City. Science and Technology Management Research, 19, 1-5.

[3] Wang, W. (2015) Regional Differences in China's Economic Growth Driven by Innovation. Journal of Northwest University (Philosophy and Social Sciences), 45, 133-137.

[4] Yin, M.J. (2015) Research on the Evaluation of the Provincial Administrative Region Innovation-Driven Development. Industrial Technology \& Economy, 12, 71-77.

[5] Hu, C.P., Li, W.H. and Wang, X.H. (2016) Innovative Province Evaluation-The Case of Shanxi. Science and Technology and Economy, 29, 26-30.

[6] Li, Q. and Xia, H.L. (2016) The Comparative Study of the Implementation of Innovation-Driven Development in Jiangsu and Beijing, Shanghai, Zhejiang, Guangdong. Suzhou University of Science and Technology (Social Science Edition), 33, 27-32.

[7] Tian, L.P. (2016) Thoroughly Implement the Strategy of Intellectual Property, Effectively Support the Innovation Driven Development. Technology and Law, 103, 72-74.

[8] Zhang, L.W. (2013) Research on the Innovation-Driven Development. China Soft Science, $1,1-5$.

[9] Shen, C.Y. (2014) Intellectual Property Drives the INNOVATION development and Supports the Development of New Economic. http://finance.cnr.cn/zt/jinh/ycbd/20141221/t20141221 517170332.shtml

Submit or recommend next manuscript to SCIRP and we will provide best service for you:

Accepting pre-submission inquiries through Email, Facebook, LinkedIn, Twitter, etc.

A wide selection of journals (inclusive of 9 subjects, more than 200 journals)

Providing 24-hour high-quality service

User-friendly online submission system

Fair and swift peer-review system

Efficient typesetting and proofreading procedure

Display of the result of downloads and visits, as well as the number of cited articles

Maximum dissemination of your research work

Submit your manuscript at: http://papersubmission.scirp.org/

Or contact ojbm@scirp.org 